\title{
Bocheński on authority
}

\author{
Anna Brożek
}

Published online: 28 August 2013

(C) The Author(s) 2013. This article is published with open access at Springerlink.com

\begin{abstract}
Józef Maria Bocheński introduced an important distinction between deontic and epistemic authority. A typical example of epistemic authority is the relation of a teacher to his students; a typical example of deontic authority is the relation between an employer and his employee. The difference between the two lies in domains of authority: declarative sentences make up the domain in the case of epistemic authority, orders - in the domain of deontic authority. In the article, I analyze in detail the concepts of the two kinds of authority and propose some new explications. The concept of epistemic authority is distinguished from the concept of infallibility and expertise; and the concept of deontic authority is distinguished from the concept of sovereign. I interpret various kinds of deontic authority in the light of the theory of imperative sentences. The concepts of gradation and degradation of authority are introduced and explicated.
\end{abstract}

Keywords Deontic authority · Epistemic authority · Józef Bocheński ·

Imperative sentence

\section{Epistemic and deontic authority}

Intuitions

What interests me most within Boceński's conception of authority is the distinction he draws between epistemic and deontic authority. Bocheński notes that we may

The article is based in part on a paper presented during the conference Józef Maria Bocheński. The Heritage of the Ideas, which took place in Bydgoszcz, October 18-20, 2012.

\footnotetext{
A. Brożek $(\bowtie)$

University of Warsaw, Krakowskie Przedmieście 26/28, 00-927 Warszawa, Poland

e-mail: abrozek@uw.edu.pl; broscius@gmail.com
} 
call someone "an authority", or describe him as enjoying someone's respect, due to the fact that he builds a ternary relationship with another person and a certain object represented by a set of sentences (resp. identified with this set). Bocheński puts this relation symbolically into the following formula:

(1) $A(x, y, \alpha)$.

where $x$ is the person who enjoys $y$ 's respect (in short: the object of authority), $y$ is the person for whom $x$ is an authority (in short: the subject of authority), and $\alpha$ is a set of sentences (the domain of authority). Formula (1) may be read as " $x$ is an authority for $y$ in the area of $\alpha$ ".

The relationship is represented in three domains: the set of subjects of the authority, that is, the set of persons who enjoy someone's respect; the set of objects of authority, that is, the set of persons who respect someone; and the set of sets of sentences. In the comments concerning intuitions connected to the notion of authority, Bocheński devotes much attention to the characteristics of these domains. We are especially interested in the characteristics of the domain of authority. ${ }^{1}$

Bocheński writes that the sentences forming the domain of authority may be of two kinds: they can be either declarative sentences (further referred to as declaratives) or imperative sentences (further: imperatives). Let us quote a relevant passus:

The field [here: domain] of authority is a class of objectively meaningful utterances. By this is meant that it must be a class of utterances, that is, of symbols perceivable by the subject, of meaningful symbols, such as may be understood by him, and finally, that it must carry some objective meaning. Only objectively meaningful utterances may be accepted by the subject, and the acceptance of them seems to be essential to the authority. [...]

There are two main classes of utterances carrying complete objective meaning, namely, sentences and imperatives. Accordingly, there are two main ways of accepting an utterance: a sentence will be accepted as true, or at least as possessing a certain probability, an imperative as binding. And if so, we have to deal with two quite different sorts of authority, according to the nature of their fields [here: domains]: the first one, that of uttering sentences, will be called here "epistemic authority"; the second, uttering imperatives, “deontic authority” (Bocheński 1965, p. 164, 166-167).

Bocheński illustrates the difference between epistemic and deontic authority with the following example:

Let us take the case of a lieutenant who is highly skilled in military science, and who is under the command of a rather unintelligent and uninstructed

\footnotetext{
1 Bocheński uses the term "area of authority" rather than "domain of authority". The former term may be deceptive because since being-an-authority is a certain relationship, then its area sensu stricto is formed from the sum of its domains. Thus, for the purposes of this paper, I shall use the term "domain of authority" rather than "area of authority." Let us also note that some may take issue with the fact that the said domain is a set of certain sentences. As it will turn out later, if person $x$ is an authority of person $y$ in the domain $z$, e.g., in the domain of philosophy, then person $y$ accepts as true those theses (and thus: sentences) of philosophy which are accepted as such by the person $x$.
} 
major [...]. This major is, for our lieutenant, a deontic authority in the field of imperatives concerning the war actions. He can command him for example to undertake an action $Q$, and the lieutenant has to accept this command as binding. But in our case the lieutenant is not bound to accept any sentence, not even the sentence corresponding to the command received: "The imperative prescribing $Q$ is tactically justified". For only an epistemic authority can prescribe a sentence, not a deontic one. In other words, the epistemic authority is that of an expert, the deontic authority that of a commander or superior. [...] It is not implied that epistemic and deontic authority always occur in separate and distinct persons. On the contrary, the normal case, for example, in the army, will be that the same person is at the same time an expert and a commander. But it does not need to be so (Bocheński 1965, pp. 167-168).

Before we analyze Bocheński's conception more closely, let me propose certain explications of the notions of epistemic authority, deontic authority, as well as some related notions. In order to explain these terms I will make use of some well-formed natural language formulas. ${ }^{2}$

Epistemic authority, infallibility and expertise

Let us begin with epistemic authority. Bocheński proposes the following definition:

$P$ est une autorité épistémique pour $S$ dans le domaine $D$ si et seulement s'il accepte en principe toute proposition appartenant au domaine $D$ que $P$ lui communique avec assertion (Bocheński 1979, p. 66). ${ }^{3}$

Although Bocheński is well known for his logical simplifications, this definition is notionally quite complicated. Here is my proposal to simplify it, where I shall use only two specific primitive notions: accepting and notifying (leaving these notions without explanation):

(2) $\wedge x \wedge y \wedge \alpha$ : $x$ is for $y$ an epistemic authority in the domain of $\alpha \leftrightarrow$ def.

(a) $V^{\prime} q$ ' (' $q$ ' $\left.\in \alpha\right): x$ accepts that $q$,

$\wedge$

(b) $\wedge$ ' $p$ ' (' $p$ ' $\in \alpha): x$ notifies $y$ that $x$ accepts that $p \rightarrow y$ accepts that $p$.

Component (a) in the definiens of the above definition is necessary in order for the antecedent in formulas (b) not to be cancellable: the point is not to call "an authority" someone who does not accept any sentence in a given domain. ${ }^{4}$

\footnotetext{
2 I am concerned with the formulas which, apart from natural language phrases, whose meanings are the simplest possible notions I shall not define, contain certain elements of the language of standard predicate calculus such as quantifiers and variables. Such notation of formulas facilitates obtaining their explicitness and a degree of clarity which would be impossible to achieve in the case of the formulas which do not use such symbols.

${ }^{3} P$ is an epistemic authority for $S$ in domain $D$ if and only if in principle $S$ accepts every sentence belonging to domain $D$ that $P$ communicated with assertion to $S$.

4 Professor Edward Nieznański drew my attention to the necessity of formulating the definition of "authority" in such a way that the antecedent of formula (b) be non-cancellable. Although I agree with him in principle, I believe it is conceivable that there are certain domains where a rational person has to
} 
Component (b) states that $y$ (the object of authority) accepts every sentence about which he is informed that $x$ accepts it. ${ }^{5}$

At this point it has to be stated clearly that the notion of epistemic authority should be distinguished from that of infallibility in a given domain as well as from the notion of expertise in a given domain (Bocheński does not use these terms but, as we will see further, he uses terms which I link with them). I propose to explain the notion of infallibility in a given domain in the following manner (I use the notion of accepting and the notion of truthfulness as specific primitive notions):

(3) $\wedge x \wedge \alpha: x$ is infallible in the domain $\alpha \leftrightarrow_{\text {def. }}$

(a) $V^{\prime} q$ ' (' $q$ ' $\left.\in \alpha\right): x$ accepts that $q$,

$\wedge$

(b) $\wedge^{\prime} p$ ' (' $p$ ' $\left.\in \alpha\right): x$ accepts ' $p$ ' $\rightarrow$ ' $p$ ' is true.

Condition (a) has been added, as in the case of formula (2), in order to avoid the consequence that one would have to accept as infallible in a given domain a person who does not accept any sentence which belongs to this domain. In addition, however, the above definition has practical value only when the number of sentences from a given domain accepted by $x$ is large enough and when the sentences have significant theoretical value within that domain.

As our cognitive powers are limited, we rarely rely on the notion of infallibility in practice. The notion of an expert seems more relevant. Let us assume for the purposes of this argument that degree of mastery of an expert in a given domain is directly proportional to the number of sentences belonging to that domain whose logical value this expert is aware of (at least potentially):

(4) $\wedge x \wedge \alpha: x$ is the better expert in the domain $\alpha$ the greater is number of such ' $p$ '-s and ' $q$ '-s which belong to the domain $\alpha$, that:

(a) ' $p$ ' is true $\rightarrow x$ accepts that $p$,

$\wedge$

(b) ' $q$ ' is false $\rightarrow x$ accepts that $\sim q$.

Explanation (4) gives an account of the relational notion of expertise. I will also propose a non-relational explanation that is more convenient for the purposes of our further considerations:

(5) $\wedge x \wedge \alpha: x$ is an expert in the domain $\alpha \leftrightarrow$ def. for most ' $p$ '-s and ' $q$ '-s belonging to the domain $\alpha$ it is the case that:

(a) ' $p$ ' is true $\rightarrow x$ accepts that $p$,

\section{Footnote 4 continued}

refrain from accepting any sentence that belongs to them. Bocheński provides no equivalent for this formulation.

\footnotetext{
${ }^{5}$ My intention is to make condition (b) express Bocheński's intuitions as precisely as possible. Still, I believe other versions of condition (b) come into play here; in particular, a condition for accepting sentence ' $p$ ' by the object of authority could be the mere fact that (i) sentence ' $p$ ' accepts the object of authority, or the fact that (ii) the object of authority accepts that the subject of authority accepts ' $p$ '. Version (i) is an interesting, but far-reaching, idealization. Version (ii) is devoid of pragmatic value to a lesser degree. Sometimes one is prone to accept as true a sentence which one only supposes that the authority accepts (as he did not inform us). To account for this, formula (ii) should be accepted as valid.
} 
$\wedge$

(b) ' $q$ ' is false $\rightarrow x$ accepts that $\sim q$.

One weakness of this definition is that a vague concept lies behind the term "most sentences belonging to the domain". However, this matter has to be left aside for now.

In fact, certain suitable "historical" parameters should be added to the above definition: the set of sentences belonging to a given domain evolves after all, and one is an expert in a given domain in a given phase of this development. (Physics in Newton's times covered a different set of sentences than it does now; thus, if one decides that $\alpha$ is a set of sentences belonging to contemporary physics, Newton would be a lesser expert on physics than an average graduate of contemporary physics.) Yet in order not to complicate the matter, I will omit these historical aspects.

I turn now to the differences between the notion of epistemic authority on the one hand and those of infallibility and expertise on the other. The notion of epistemic authority is a derivative of a ternary relation: one is an epistemic authority within a certain domain and for someone, whereas one is infallible and an expert simply in relation to a certain domain, but not in relation to some other person. One may say that the notions of infallibility and expertise are "absolute," contrary to the "relative," notion of epistemic authority. In the light of the above definitions, it also becomes clear that the notions of deontic authority and infallible person are independent: someone who is an authority for us in a given domain may obviously be in the wrong. On the other hand, it is sometimes the case that someone who is an expert in a given domain is not an authority for anybody in that domain. ${ }^{6}$

Deontic authority, obedience and sovereign

Let me now explain the notion of deontic authority. At various places of his works, Bocheński presents various intuitions concerning this notion. I will begin with those in which he attempts to maintain the closest analogy between the notion of deontic authority and that of epistemic authority. For instance, he writes that when a deontic authority "communicates" a certain prescription, the object of the authority is to "accept it as valid".

Let us assume that every prescription is the content of an imperative. I propose to interpret the relationship of deontic authority by using the following predicates as specific primitive notions: "wants that", "executes an imperative", "is valid", "accepts that", "should". The following explanations seem to come closest to Bocheński's concept:

(6) $\wedge x \wedge y \wedge \beta: x$ is a deontic authority for $y$ in the domain $\beta \leftrightarrow$ def.

$\wedge i(i \in \beta): x$ informs $y$ that $x$ wants $y$ to fulfill $i \rightarrow y$ accepts that $y$ should fulfill $i{ }^{7}$

\footnotetext{
6 Assuming, as Bocheński does, that no one is an authority for themselves.

7 Perhaps also here we should assume per analogiam that in order to be a deontic authority for someone, one has to communicate at least one prescription to the object of the authority. On the other hand, in order for a person to be a deontic authority for someone, it may suffice that someone is prepared to fulfill his directives. Similarly, in the case of definition (2), two other versions of the antecedent of the definiens are
} 
Thus explained, the notion of deontic authority has to be differentiated from the notion of full obedience to someone's will, in which case we would have:

(7) $\wedge x \wedge y \wedge \beta: y$ is absolutely obedient to $x$ in the domain $\beta \leftrightarrow_{\text {def. }}$ $\wedge i(i \in \beta): x$ communicates to $y$ that $x$ wants $y$ to fulfill $i \rightarrow y$ fulfills $i{ }^{8}$

The consequent of the definiens contains " $y$ fulfills $i$ " instead of " $x$ decides that $y$ should fulfill $i$ ". Naturally, it is one thing to accept someone's command as valid (especially if it is locally valid) and quite another to execute it. Sometimes one refrains from executing a command which one had deemed valid, whether intentionally (e.g., because of other imposed obligations whose execution excludes the obligation in question) or unintentionally (e.g., forgetfulness).

It is even more important to differentiate between the notion of deontic authority and the notion of sovereign. I propose to interpret the latter notion in the following manner:

(8) $\wedge x \wedge y \wedge \beta: x$ is sovereign in relation to $y$ in the domain $\beta \leftrightarrow$ def.

$\wedge i(i \in \beta): x$ informs $y$ that $x$ wants $y$ to fulfill $i \rightarrow y$ is obliged to fulfill $i{ }^{9}$

It is worth emphasizing that it is one thing to accept being obliged or, in other words, the feeling of obligation (see formula 6), and quite another actually to have an obligation. The latter is in turn fundamentally different from fulfilling an obligation. Sometimes one feels obliged to do something, although de facto one is not obliged; conversely, one may be obliged to do something, although one does not accept the obligation (one does not have the sense of obligation). Sometimes one does not do something one is obliged to do, or one does something that one does not feel obliged to do.

Thetic and teleological duty

At this point, there arises the question of how to interpret an obligation in the case of the relationship of being-sovereign, the occurrence of which is accepted by someone for whom another person is a deontic authority. In my view, it concerns only, or at least mostly, thetic duty, that is, the duty of sanctions.

Here is how I propose to explain this term.

Let us assume that for the states of affairs determined by sentences ' $p$ ' and ' $q$ ' there obtain relationships expressed in the following formulas:

\footnotetext{
Footnote 7 continued

worth considering, namely: (i) $x$ wants $y$ to perform $I \rightarrow y$ accepts that $y$ should fulfill $i$; (ii) $y$ decides that $x$ wants $y$ to fulfill $I \rightarrow y$ decides that $y$ should fulfill $i$. Here as well version (i) seems to be a far-reaching idealization, whereas in the case of version (ii) the idea is that sometimes the object of authority may "guess" the will of the subject of authority even though the latter does not communicate his wishes.

8 The phrase " $y$ fulfills $i$ " in this formula and further on is to be interpreted as an idealizational phrase; in all these cases the idea is that, to speak freely, $y$ takes any available measures to fulfill $i$. The antecedent of the definiens could have analogous versions, as in the case of definition (3) - see footnote 6.

9 Analogously to the previous formulas, other forms of the antecedent of the definiens are worth considering: " $x$ wants $y$ to fulfill $i$ ", and " $y$ resolves that $x$ wants $y$ to fulfill $i$ ".
} 
(9) $\wedge x: x$ 巴 causes that $p \rightarrow V_{z}(z$ is a vital good): $z$ is shared by $x$.

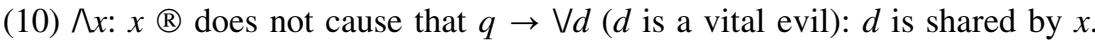

By "vital good" I mean gaining life, health or property, and by "vital evil” I mean losing life, health or property. ${ }^{10}$ Naturally, such relationships are rarely without exception; still, with recourse to idealization, I will leave a universal quantifier in (9) and (10). ${ }^{11}$ The source of the fact that (9) and (10) occur is a natural pattern (e.g., whenever someone takes poison, he dies or at least suffers badly). Yet, the source of the fact that (9) and (10) occur may also be someone's resolution; that person is then usually responsible for enforcing the fact that (9) and (10), that is, punishing anyone who sees to it that $p$, or rewarding anyone who sees to it that $q$. The vital evil alluded to above is called "a negative sanction," whereas a vital good is called "a positive sanction". In these instances the relationships (9) and (10) are established rather than natural.

Therefore, we shall say that:

(11) $\wedge x \wedge$ ' $p$ ' $[$ resp. $\wedge i]: x$ is thetically obliged to see to it that $p$ (resp. fulfill $i) \leftrightarrow_{\text {def. }}$ (a) $\bigvee s_{\mathrm{n}}\left(s_{\mathrm{n}}\right.$ is a negative sanction): $x$ does not see to it that $p \rightarrow x$ will be subjected to $s_{\mathrm{n}}$, $\checkmark$

(b) $\bigvee s_{\mathrm{p}}\left(s_{\mathrm{p}}\right.$ is a positive sanction): $x$ sees to it that $p \rightarrow x$ will obtain $s_{\mathrm{p}}$.

In other words: making a given state of affairs occur is one's thetic duty if a positive sanction will be the consequence of fulfilling that state of affairs or if a negative sanction will be the consequence of not fulfilling that state of affairs. In formula (11), the phrases "will be subjected to a negative sanction" and "will obtain a positive sanction" are obviously another idealization. In fact, the perpetrator is merely under the threat of an appropriate sanction. After all, it may be the case that the offense remains undetected or the sanction is not imposed. Obviously, it would not be too much trouble to include these cases in formula (11); however, for the sake of simplicity I will not do so.

Based on individual thetic relationships, one is able to define only the notion of local duty (in other words: prima facie duty), and this kind of duty is described in formula (11). The question of how to "calculate" someone's global duty (in other words: per saldo duty) is very interesting, but is not essential for the present considerations.

Yet, in my opinion, it is essential to distinguish the notion of thetic duty from the notion of teleological duty. Let me explain the difference.

Assume that for states of affairs determined by sentences ' $p$ ' and ' $q$ ' there occurs a natural pattern:

(12) $\wedge x: x$ will not see to it that $p \rightarrow$ it will not occur that $q$.

as well as:

\footnotetext{
10 These notions and the separate notions of moral good or evil are further analyzed by me together with J. Jadacki in Brożek and Jadacki (2006).

11 Another idealization in formulas (9)-(11) disregards the fact that the occurrence of consequents is the consequence (at least temporal) of the occurrence of antecedents.
} 
(13) A wants to see to it that $q$.

We can state that based on pattern (12) and in view of the objective described in (13):

(14) $A$ should see to it that $p$.

Duty (14) is the teleological duty of a given person. Let us note that teleological duty is relativized to a certain "natural" relationship (that is, a pattern which is not introduced with the help of someone's act of will) and to a certain objective. One is teleologically obliged to bring about a certain state of affairs when this state of affairs is a necessary condition for realizing one's objective. Naturally, as we are once again dealing with local teleological duty, I will leave aside the question of what is one's global duty in this case.

At this point, the question arises whether the aforementioned duties are reducible to one another.

With certain assumptions, one may state that thetic duty is reducible to teleological duty since avoiding a negative sanction or achieving a positive sanction connected to a certain action can sometimes constitute one's objective.

With slightly different assumptions, one may state that teleological duty is reducible to thetic duty, since every pattern is established by someone, and, in particular, laws of nature, being the foundations of teleological duties, are established by God.

Yet, I believe that the difference between the two types of duty is vital and in consequence neither of them is reducible to the other. On the one hand, natural patterns differ from established ones (if we accept that God establishes the laws of nature, we need to recognize nevertheless that they differ in kind from thetic relationships sensu stricto). On the other hand, in order to characterize thetic duty there is no need for the notion of objective at all: one has a thetic duty whether or not one's objective lies in avoiding a negative sanction or obtaining a certain good. $^{12}$

\section{Bocheński's notion of authority-a closer analysis}

The explanations proposed in "Epistemic and deontic authority" section can now serve as means to a more thorough analysis of Bocheński's concept of deontic and epistemic authority.

Bocheński writes:

Le poète fait tenir au diable le langage suivant: «Tenez-vous aux mots! Alors vous entrerez par la bonne porte dans le tempe de la certitude». Or, quoique ce conseil vienne du diable, il paraît de prime abord tout à fait raisonnable. Nous commençons toujours par faire confiance aux mots, par

\footnotetext{
12 I will ignore the question of whether there exists a third kind of duty, that is, moral duty. On this issue, see Brożek (2012).
} 
croire que nous les comprenons bien et nous les utilisons sans hésiter (Bocheński 1979, p. 25). ${ }^{13}$

Bocheński was one of few who paid special attention to notional distinctions and who noted confusions concerning terminology. Besides, he regarded conceptual analysis as the essence of philosophy. This is why I am certain he would be glad to learn that his papers, too, contain certain conceptual inconsistencies, which needed correction. Here are some among them.

\section{Meanings of "authority"}

Bocheński is well aware of the difference between being-an-authority as a relationship and having-authority as a character trait. Indeed, we sometimes say, "Mr. Smith has authority", meaning thereby that Mr. Smith possesses a certain trait which ensures other people's obedience. The difference between a relationship and a trait may be indistinct because the trait is discretionary and is only revealed in certain social situations. In other words, whether or not someone has authority-as-atrait becomes clear when he enters the relationship of being-an-authority-for-others with ease.

In my view, Bocheński does not clearly distinguish other meanings of the term "authority," although many of his remarks indicate that he sensed the differences to a lesser or greater degree.

In Bocheński's formulations, which I will interpret as definitions, the meaning he gives to the term "epistemic authority" corresponds to my formula (2), whereas what he means by "deontic authority" corresponds to my formula (6). But Bocheński ascribes two additional meanings for these terms in formulations of an extra-definitional nature. I am referring to the meanings of "epistemic authority" explained above in formulas (4) and (5), that is, the meanings of the term "expert" and that of "deontic authority" explained above in formula (8), viz., the meaning I attach to the term "sovereign."

The explanations presented in $\S 1$ indicate clearly that the notion of epistemic authority differs from that of expert and the notion of deontic authority differs from that of sovereign. Both are-and here I agree with Bocheński- "relative": it is not assumed about the subject of authority that any of his statements we take "for granted" are true and that he is thereby ipso facto an expert in the given domain. Nor is it said of a deontic authority that he also has legitimate power over the object of authority, that is, that he is the object's sovereign. It is more likely that other factors determine whether or not an expert becomes an epistemic authority, or a sovereign becomes a deontic authority: among other things, whether he has authority as a character trait.

Some of Bocheński's remarks testify to the fact that he was not always aware of the fundamental difference between the respective concepts.

\footnotetext{
${ }^{13}$ As the poet has the devil say: "First of all, stick to the words! Thus you will enter the temple of certainty through the right door." Although this advice comes from the devil, it seems prima facie reasonable. After all, we always start by trusting words, believing that we understand them well, and use them without hesitation.
} 
Let us begin with the following remark:

L'enfant est pour nous une autorité dans le domaine des informations sur ses maux d'estomac. Et cela est raisonnable, car personne ne peut savoir mieux que l'enfant s'il ressent ou non ces douleurs. [...] Pour qui est-il une autorité? Nous disons, pour tous les autres hommes-car tous sont dans la même situation que nous: l'enfant en sait plus qu'eux à ce sujet (Bocheński 1979, p. 54). ${ }^{14}$

In fact, a child is only an expert in the said domain; all the same, however, not everyone will accept the child's reports. It seems that rational people aware of the child's expertise would acknowledge his authority in the domain.

In keeping with Bocheński's definition of "epistemic authority," it is false to claim, as he does, that:

Il existe au moins un homme qui, dans au moins un domaine, est au autorité pour tous les autres hommes (Bocheński 1979, p. 224). ${ }^{15}$

and especially:

Tout homme est au moins dans un domaine une autorité pour tous les autres hommes [Ibid.]. ${ }^{16}$

Bocheński confuses the notion of authority with those of expert and sovereign in the following statement about God:

Dieu est le concept limite de l'autorité. [...] $P$ est porteur d'autorité envers tous les sujets et dans tous les domaines si, et seulement si $P$ est Dieu (Bocheński 1979, p. 56). ${ }^{17}$

At best, God is an omni-expert (or even an omniscient entity) or an omnisovereign, and would remain God even if no one accepted the sentences and directives communicated by it.

Abusing authority

In the course of his considerations on the abuse of authority, Bocheński notices a weakness in his definition of "authority," or rather, a theoretical "discord" between this definition and his other remarks on authority. Discussing an example of a student who accepts the sentences uttered by his chemistry professor concerning the Vietnam War, Bocheński observes that there are good theoretical reasons to differentiate between epistemic authority and a justified deontic authority. Since the

\footnotetext{
14 A child is an authority for us in the domain of information concerning its stomachache. And this quite reasonable since no one can know better than the child the pain she experiences. [...] For whom is he an authority? We say that he is an authority for all people, as all other people are in the same situation: the child knows more than they about the matter.

15 There is at least one human who is an authority in at least one domain for all other humans.

16 Every human is an authority for other humans in at least one domain.

17 God is a boundary notion of authority. [...] $P$ is the bearer of authority with respect to all subjects and in all domains if and only if $P$ is God.
} 
student accepts the chemistry professor's sentences relative to a domain different from chemistry, then according to the definition proposed by Bocheński, the student also recognizes the professor as an epistemic authority in that other domain. Bocheński remarks:

L'autorité du professeur de chimie est fondée relativement à la chimie, mais relativement à la guerre du Vietnam, cette autorité est une autorité abusive (Bocheński 1979, p. 57). ${ }^{18}$

A probable definition of justified authority, in the light of the definitions proposed in "Epistemic and deontic authority" section is:

(15) $\wedge x \wedge y \wedge \alpha$ : $x$ is a valid epistemic authority for $y$ in the domain $\alpha \leftrightarrow$ def. $x$ is an epistemic authority for $y$ in the domain $\alpha$

$\wedge$

$x$ is an expert in domain $\alpha$.

The notion of expertise is generally gradable. Sometimes Bocheński claims that in order to be a valid epistemic authority for someone in a given domain it suffices to have "greater competence," that is, to be a greater expert within that domain than the other person. Thus, in the absence of further assumptions, the example of the student and the chemistry professor is inconclusive, as it is not impossible that the professor is more competent than his student is in matters concerning the Vietnam War. This interpretation is suggested by Bocheński's formulation:

$P$ est une autorité pour $S$ dans le domaine $D$ lorsque $P$ connaît ce domaine mieux que $S$ (Bocheński 1979, p. 82). ${ }^{19}$

According to Bocheński, authority is abused when "the subject of authority attempts to extend his authority to domains in which he is not entitled to have such authority," or when "he pretends to be an authority over an object or in a domain in which he does not possess in fact valid authority". He adds:

Un exemple classique est celui de ces savants professeurs qui font des déclarations politiques et qui donnent ainsi l'impression d'être des autorités en matière de politique, alors qu'il ne sont compétents qu'en paléographie, en égyptologie, en physique ou en géographie de la lune. [Un autre exemple concerne le cas où] on cherche à exercer une autorité sur des sujets sur lesquels on n'a pas d'autorité; ainsi lorsqu'un sous-officier donne des ordres non seulement à ses soldats, mais également à des civils (Bocheński 1979, p. 56). ${ }^{20}$

\footnotetext{
18 The professor of chemistry has a justified authority in the domain of chemistry, whereas relative to the Vietnam War his is an abuse of authority.

${ }^{19} P$ is an authority for $S$ in the domain $D$ under the condition that $P$ knows the domain $D$ better than $S$.

20 A classic example of this kind of abuse is the case of those learned professors who make political declarations thereby creating the impression that they are authorities in matters of politics, whereas they are competent only in paleography, egyptology, physics or lunar geography. Another kind of abuse occurs when a person attempts to demonstrate authority in regard to subjects over whom he does not have authority: for instance, when an officer issues orders to civilians as well as to his soldiers.
} 
It is worth asking what it means in practice to "extend (epistemic) authority" or "pretend to it." Though Bocheński does not say so directly, he seems to have in mind a more or less deliberate manipulation of the objects of one's own authority. In my opinion, it consists mainly in communicating "emphatically," as Bocheński calls it, one's views in a given domain to others while fully aware that one is not an expert in this domain, or at least not to a greater degree than those addressed. Thus we would have:

(16) $\wedge x \wedge y: x$ abuses his epistemic authority over $y \rightarrow$

(a) $x$ resolves that $x$ is an epistemic authority for $y$ in the domain $\alpha$, $\wedge$

(b) $x$ resolves that $x$ is not an expert (resp. is not a greater expert than $y$ ) in the domain $\alpha^{\prime}$,

$\wedge$

(c) $x$ communicates to $y$ emphatically that $x$ accepts certain sentences which belong to the domain $\alpha^{\prime}$.

Notice that the above formula contains only an implication instead of equivalence. This is because it is unclear how to distinguish the abuse of authority in a given domain from other situations where conditions (a)-(c) hold but there is no abuse of authority, as, for example, in a discussion between $x$ and $y$ on a certain problem in the domain $\alpha$. The person $x$ would have to make deliberate use of a some psychological advantage over the person $y$. In the following remark, Bocheński argues for such reading:

D'un point de vue psychologique, l'acceptation de la fausse autorité s'explique, dans la plupart des cas, par l'habitude (Bocheński 1979, p. 58). ${ }^{21}$

Bocheński holds, finally, that there are domains in which the abuse of authority occurs especially frequently:

Il y a toute une série de sciences malheureuses-ainsi l'énonomie politique, la sociologie, la philosophie, la théologie, la stratégie, sans parler de la "futurology" dont beaucoup de gens parlent comme s'ils y connaissent quelque chose. On les appelle volontiers des «économistes de café», des «stratèges de bistrot», etc. [...] Tout cela ne serait que ridicule si ce n'était pas si déraisonnable, donc si triste (Bocheński 1979, p. 58). ${ }^{22}$

Psychological probability

In one of his explications, Bocheński uses the term "sentence probability":

$P$ est une autorité épistémique pour $S$ dans le domaine $D$ lorsque la probabilité de la proposition appartenant à $D$-relativement à l'état de savoir de $S$-est

\footnotetext{
21 From the psychological point of view, accepting a false authority may be explained as a force of habit.

22 There are many unfortunate disciplines, such as political economy, philosophy, theology, strategy, not to mention "futurology," about which everyone talks as if they knew something about them. One may describe such people as "armchair economists," "armchair strategists," etc. [...] This would all be amusing were it not so unreasonable and therefore so sad.
} 
augmenté par la communication de cette proposition par $P$ à $S$ (Bocheński 1979, p. 68). ${ }^{23}$

The term "sentence probability" has a psychological meaning in Bocheński's papers. According to this meaning, probability is the relationship of a sentence to a given state of affaris. Relative to the state of my knowledge, the probability of a sentence about tomorrow's weather is smaller than the probability of this sentence relative to the state of meteorologist's knowledge (Bocheński 1979, p. 67).

In addition, a person's state of knowledge is "a class of all sentences which the person accepts as true". This understanding of probability is the same as the degree of conviction as to the veracity of a given sentence. The more "probable" (in this understanding) a certain sentence is, based on one's knowledge, the more conviction one manifests when accepting (resp. willing to accept) the sentence as true.

Two factors determine, according to Bocheński, whether the probability of a sentence (that is, the degree of one's conviction about the veracity of that sentence) grows when someone "communicates it emphatically" (that is, informs someone that he accepts it):

Qu'est-ce qui est nécessaire pour que la probabilité de la dite proposition augmente? [...] Il faut admettre deux qualités du porteur: une compétence supérieure à la mienne et sa véracité. [...] La reconnaissance d'une plus grande compétence et la véracité dans un domaine est une condition nécessaire de l'autorité épistémique. [...] Il est peu probable ... que nous considérions comme une autorité un ... menteur. Il semble donc bien que la confiance soit impliquée dans la notion d'autorité (Bocheński 1979, pp. 68-69). ${ }^{24}$

This formulation is intuitively right. Indeed, if one does not accept what someone says, either one does not trust the speaker or one does not acknowledge his expertise. Naturally, in practice, various irrational factors, such as emotions, often decide whether someone's opinion counts. However, if someone communicates a belief to someone who rejects it this is a sure indication that the speaker is bereft of epistemic authority.

We should add, too, that sentences uttered by someone considered to be a liar are not accepted as true. It may be the case that someone does not know that the speaker is a liar. We say one was misled in a situation where one accepts someone's competence and trusts him, but that person lied.

\footnotetext{
${ }^{23} P$ is an epistemic authority for $S$ in the domain $D$ when the probability of every sentence, which belongs to $D$-relative to the state of $S$ 's knowledge-, grows by virtue of the communication of this sentence to $S$ by $P$.

24 What is necessary for the probability of a sentence to grow? [...] we need to recognize two qualities of the bearer: competence superior to mine and his veracity. [...] Recognizing the bearer's superior competence and veracity in the domain is a necessary condition of epistemic authority. It is hardly likely... that we would consider a... liar as an authority. It seems therefore that trust is contained in the concept of authority.
} 
Justification of authority

Bocheński asserts:

L'acceptation d'une autorité épistémique sans justification aucune est moralement irrecevable (Bocheński 1979, p. 70). ${ }^{25}$

On the other hand, he is a firm opponent of the view that there are no (or: there should be no) epistemic authorities. According to Bocheński, accepting someone as an epistemic authority may be justified, and accepting justified epistemic authorities is completely rational. Bocheński mentions two ways to justify accepting someone's epistemic authority. We can call them, respectively, "individual" and "general." Both bear the marks of fallible reasoning, that is, generalizations based on experience.

For the case of individual justification:

(17) $\wedge$ ' $p$ ' $\wedge x \wedge \alpha$ : (' $p$ ' belongs to the domain $\alpha \wedge x$ communicated that $x$ accepts that $p) \rightarrow$ ' $p$ ' proved to be true.

Therefore:

$\wedge^{\prime} p$ ' $\wedge x \wedge \alpha$ : (' $p$ ' belongs to the domain $\alpha \wedge x$ communicated that $x$ accepts that $p) \rightarrow x$ will prove to be true. ${ }^{26}$

I quote the awkward phrases: "communicated," "will communicate," "proved to be true" and "will prove to be true" as abbreviations which could be expanded with appropriate temporal parameters. The phrase "prove to be true" is worth noting. It indicates that the views communicated by a speaker need to be checked with reality in order to justify individually accepting the speaker as an authority.

A general justification applies when the subject of authority belongs to a set (for instance, one trusts a doctor, as doctors are trustworthy, etc.). Thus, we get the following reasoning:

(18) $\wedge$ 'p' $\wedge x \wedge Z \wedge \alpha$ : (' $p$ ' belongs to the domain $\alpha \wedge x$ communicated that $x$ accepts that $p \wedge x \in Z) \rightarrow$ ' $p$ ' proved to be true.

Therefore:

$\wedge$ 'p' $\wedge y_{\neq \mathrm{x}} \wedge Z \wedge \alpha$ : (' $p$ ' belongs to the domain $\alpha \wedge x$ will communicate that $x$ decides that $p \wedge y \in Z) \rightarrow$ ' $p$ ' will prove to be true. ${ }^{27}$

As can be seen, the reasoning supposed to justify the fact that someone is an epistemic morality is fallible (see Bocheński 1965, p. 249).

\footnotetext{
25 Accepting an epistemic authority without any justification is unacceptable for moral reasons. Salamucha uses a kinder term: gullibility (see Salamucha 1936).

26 Bocheński claims: "What Mr. Smith said in domain $D$ proved to be true numerous times"-a generalization: "He will always be right."

27 Bocheński claims: "Many doctors are truthful and competent. This person is a doctor. Therefore, this person is truthful and competent."
} 
Deontic authority versus sovereign

I turn now to questions concerning the notion of deontic authority. First, Bocheński did not see a clear distinction between the notions of deontic authority and that of the sovereign. This is clear from his remarks on delegating deontic authority. He writes:

Il y a délégation lorsque le porteur remet (ou transmet) à une autre une partie de son autorité-ainsi, par exemple lorsque la mère, qui doit aller faire ses courses, dit aux plus jeunes de ses enfants: «Pendant que je serai en ville, obéissez bien à Isabelle». Ici l'autorité maternelle est remise, déléguée à la «grande» fille-qui n'a jamais que 14 ans (Bocheński 1979, p. 96). ${ }^{28}$

I believe a sovereign can delegate his duties but not his authority. Thanks to her mother's decision, the oldest daughter acquires "power" over her younger siblings, but the mother does not make the children recognize their sister's directives as valid only by taking the decision.

\section{Kinds of deontic authority}

Another issue concerning deontic authority has to do with Bocheński's distinction between the authority of sanctions and the authority of solidarity. He says, firstly:

$P$ est une autorité déontique pour $S$ comme appartenant au groupe $G$, dans le domaine $D$, si et seulement s'il existe un événement $B$ tel que $S$ croit que l'éxécution de toutes les injonctions de $P$ appartenant à $D$ par la plupart des membres de $G$, est une condition nécessaire de la réalisation de $B$ [..] (Bocheński 1979, p. 92) ${ }^{29}$

In this formulation, Bocheński focuses on the reasons why the object of authority accepts as valid the prescriptions of the subject of authority. (NB. He does not do so in the case of epistemic authority.) The reason is that the person has some objective in mind (something that he wants) as well as some idea about how to achieve the objective. For the notion of deontic authority to be analogous with that of epistemic authority, the formulations concerning the reason for accepting the prescriptions as valid cannot be part of this definition. Unfortunately, the one general weakness of Bocheński's considerations on authority is that he does not differentiate between definitions and factual sentences: he simply calls all the quoted formulas "statements".

I will look more closely now at Bocheński's remarks on the two kinds of deontic authority just mentioned: the authority of sanctions and the authority of solidarity. At one point, he states:

\footnotetext{
28 Delegation occurs when the bearer transfers (or transmits) a part of his authority to somebody else. For instance, when a mother goes shopping and tells her the youngest of her children: "Listen to Isabelle when I'm gone." In this case, the mother delegated her authority to the girl (who, at 14, is the oldest). ${ }^{29} P$ is a deontic authority for $S$ as belonging to the group $G$, in the domain $D$, if and only if there exists an event $B$ of a kind such that $S$ believes that executing all of $P$ s injunctions belonging to $D$ by most of the members of $G$ is a necessary condition for the realization of B [...].
} 
Deontic authority can be devided into [...] authority of sanctions (where the authority's objective is different from mine but I obey his orders for fear of penalty) and authority of solidarity (where we both have the same objective, for instance, when sailors have the same objective as their captain in a dangerous situation) (Bocheński 1994, p. 24).

Bocheński analyzes the difference between these two kinds of authority by distinguishing an immanent from an transcendent objective (or in other words, a proximal and a distant objective), where a transcendent objective is one to which an immanent objective is subordinate. For example, if the transcendent objective is to graduate from university, the immanent objective would be to pass the A-levels. Bocheński writes further:

Une autorité déontique est une autorité de sanction si et seulement si (1) les buts transcendants du porteur et du sujet sont différents et et si (2) le lien entre l'action et le but transcendant du sujet est créé par la volonté du porteur. [...] [M]ême lorsqu'il y a une menace-le cas d'un navire en détresse (editor's addition) - celle-ci est d'une autre nature que dans l'autorité de sanction. La différence consiste en ceci, que le lien entre le but immanent et le but transcendant n'est plus ici créée par la volonté du porteur, mais existe indépendamment de lui. Par exemple, ce n'est pas le capitaine qui a déterminé que si l'eau n'est pas évacuée, la navire coulera, mais une loi physique totalement indépendant de sa volonté. [...]

Une autorité déontique est une autorité de solidarité si et seulement si (1) le but transcendant du porteur et du sujet sont identiques et si (2) le lien entre l'action du sujet et son but transcendant est indépendant de la volonté du porteur (Bocheński 1979, pp. 107-108). ${ }^{30}$

Distinguishing the two kinds of objective and distinguishing between the situation when two people's objectives are compatible and the situation when they are incompatible is a reasonable idea. ${ }^{31}$ I also fully agree with Bocheński in that we should distinguish between a relationship established through an act of will and a relationship that is independent of any act of will. However, I can hardly accept the idea according to which the person uttering an imperative remains a deontic authority despite invoking some natural regularity.

This issue requires further explanation.

\footnotetext{
${ }^{30}$ Deontic authority is an authority of sanctions if and only if (1) the transcendent objectives of the bearer and the subject of authority differ and (2) the relationship between subject's action and his transcendent objective is established by the of the bearer. [...]

In a dangerous situation, for instance, when a ship is sinking, the nature of the danger differs from that in the case of an authority of sanctions. The difference is that here the relationship between immanent objective and transcendent objective is not created through the bearer's will but exists independently of it. For instance, it is not the captain who decides that the ship will sink if the water is not pumped out but a law of physics wholly independent of his will. [...]

Deontic authority is an authority of solidarity if and only if (1) the transcendent objective of the bearer and the subject of authority are identical and (2) the relationship between the subject's action and his transcendent objective are independent of the bearer's will.

31 Tadeusz Kotarbiński introduced analogous distinctions within his praxeology.
} 
The domain of deontic authorities consists of directives that we assume are in the form of imperatives. Let us suppose that the general form of imperatives is as follows:

(19) $y$, see to it that $p$.

In its prescriptive function, utterance (19) expresses the speaker's desire to make the receiver see to it that $p$. Recall now the definition of "sovereign": if a sovereign informs a person "under his rule" that he wants that person to see to it that $p$, then ipso facto he obliges the person thetically (that is, under threat of sanctions) to see to it that $p$. Thus, uttering an imperative results in a new thetic obligation (traditionally, this function of imperatives is called "performative," or "generative," as an obligation is generated in the described circumstances). Additionally, if the person uttering the imperative is a deontic authority with respect to the receiver, the receiver regards him as a sovereign, accepting thus that he is obliged to execute the imperative under threat of sanctions.

The situation is different in the case of the "authority of solidarity". An imperative in the form of (19) can be uttered in the instructive rather than the prescriptive function. In the former, the speaker does not express (or at least does not always express) the desire for the recipient to fulfill a given imperative. Neither does he establish any thetic obligation. The speaker merely communicates that fulfilling the imperative is a necessary condition to achieve an objective, usually the recipient's presumed objective. This is why imperatives with instructive meaning often assume the conditional form:

(20) $y$, if you want to see to it that $q$, then see to it that $p$.

Naturally, the fact that $q$ is the objective, and the fact that $p$ is the means to realize this objective. Thus, instruction is based on a (at least presumed) natural relationship between the fact that $p$ and the fact that $q$. Since there is a certain natural relationship (of the type: if not- $p$, then not- $q$ ) and at the same time the fact that $q$ is the aim of the recipient of the instruction, then person uttering the instruction makes the recipient aware of his thetic duty (with respect to the corresponding relationship and aim). Since the recipient believes the instruction does not oblige him thetically, but instead makes him aware of a certain natural relationship, the recipient treats the speaker as an epistemic rather than a deontic authority. $^{32}$

In Bocheński's example, if by order of the captain a member of the crew feels obliged to do something because he fears sanctions, he considers his captain to be a deontic authority. However, in case he obeys the instructions because he wants to prevent the ship from sinking, and he is convinced that the captain knows how to prevent this, he regards the captain as an epistemic authority. Yet, the example with the ship may be misleading as the captain's objective is the same as that of the crewmembers. Still, it can certainly be the case that one may instruct someone as to how to achieve an objective, even though one does not set this objective for oneself.

\footnotetext{
32 For a broader discussion of the prescriptive and instructive meanings of imperatives see Brożek (2012).
} 
Gradation and de-gradation of authority

It is sometimes said that $x$ is a greater authority that $y$, or that $x$ is an unquestionable authority (in a given domain). It is also said that $x$ lost his authority or that $x$ ceased to be an authority for someone.

How to explain these notions based on the preceding considerations?

If we chose to follow the "working" characteristics of epistemic authority proposed by Bocheński, we would have to admit that $x$ 's being a greater epistemic authority for someone than $z$ would be manifested in a situation where $x$ and $z$ disagree and we accept as true whatever $x$ accepts and communicates to us. Thus,

(21) $\wedge x \wedge y \wedge z \wedge \alpha: x$ is a greater epistemic authority for $y$ than $z$ in the domain $\alpha$ $\leftrightarrow$ def.

$\vee^{\prime} p$ ': ' $p$ ' $\in \alpha \wedge x$ communicates to $y$ that $z$ accepts that $p \wedge z$ informs $y$ that $z$ accepts that not $p \wedge y$ accepts that $p$.

Appeal to the notion of expertise likewise helps explain the gradation of epistemic authority, especially in its relative form. We will say that:

(22) $\wedge x \wedge y \wedge z \wedge \alpha: x$ is a greater epistemic authority for $y$ than $z$ in the domain $\alpha$ $\leftrightarrow$ def. $y$ accepts that $x$ is a better expert on the domain $\alpha$ than $z$.

We should add that $y$ trusts both $x$ and $z$ (or at least $x$ ).

By analogy to the notion of epistemic authority, the notion of gradation of deontic authority should be explained as follows:

(23) $\wedge x \wedge y \wedge z \wedge \beta$ : $x$ is a greater deontic authority for $y$ than $z$ in the domain $\beta \leftrightarrow$ def. $\vee i: i \in \beta \wedge x$ communicates to $y$ that $x$ wants $y$ to fulfill $i \wedge z$ communicates to $y$ that $z$ wants $y$ not to fulfill $i \wedge y$ decides that $y$ should fulfill $i$.

The above applies to situations where $y$ considers $x$ to be a "mightier" sovereign than $y$, and it probably goes without saying that there are grades of sovereignity (for instance, in the army, in companies, etc.).

Bocheński emphasizes that referring to an epistemic authority is the weakest kind of justification for accepted arguments. Direct evidence or reasoning that is "logically stronger" than appeals to authority are much more powerful justifications. Therefore, we may suppose that whenever someone "ceases to be an authority for one" or "loses authority" the sentences he accepted have been shown to be false, based on other types of justification.

Although Bocheński used to say that a philosopher's task is to analyze rather than moralize, his remarks on authority certainly have a moralizing character. Let us only recall his remarks on how much confusion may result from confusing authorities in practical life, especially by failing to distinguish between an epistemic authority and a deontic authority. I will end by quoting a relevant passage from One Hundred Superstitions:

An example of a particularly harmful prejudice consists in confusing a deontic authority (a boss) with an epistemic authority (an expert). Many people imagine that whoever holds power, and is, thus, a deontic authority, is at the 
same time an epistemic authority and can instruct his subordinates, e.g., on the topic of astronomy. Once I witnessed a "lecture" delivered by an officer, who was ignorant in the field of astronomy, to a squadron including a soldier with a $\mathrm{PhD}$ in astronomy. Even distinguished figures sometimes fall prey to this mistaken belief, such as St. Ignatius of Loyola, the founder of the Society of Jesus, who required Portuguese members of the Order to "submit their judgment to their superior", that is, to a purely deontic authority (Bocheński 1994, pp. 25-26).

The arguments presented above are of a rather modest, purely theoretical nature. My main objective has been to demonstrate the direction of further investigation of the notion of epistemic and deontic authority, initiated by Bocheński.

Acknowledgments This article is supported by the project "The Significance of the Lvov-Warsaw School in the European Culture" (Foundation for Polish Science).

Open Access This article is distributed under the terms of the Creative Commons Attribution License which permits any use, distribution, and reproduction in any medium, provided the original author(s) and the source are credited.

\section{References}

Bocheński, J. M. (1965). Analysis of authority. In The logic of religion (pp. 162-173). New York: New York University Press.

Bocheński, J. M. (1979). Qu'est-ce que l'authorité? Introduction à la logique de l'autorité. Fribourg (Suisse): Editions Universitaires.

Bocheński, J. M. (1994). Sto zabobonów [One hundred superstitions]. Kraków: Philed.

Brożek, A. (2012). Teoria imperatywów i jej zastosowania [Theory of imperatives and its applications]. Krakow: Copernicus Center Press.

Brożek, A., \& Jadacki, J. (2006). Ethica-terra ubi leones. Przeglad Humanistyczny, 5-6, 163-169.

Salamucha, J. (1936/1997). Faith. In Wiedza $i$ wiara [Knowlege and faith] (pp. 113-121). Lublin: TN KUL. 